\title{
Comparative Analysis of Haematological Indices of Haemoglobin Genotypes Aa, Ac, As, Sc And Ss - A Retrospective Study.
}

\author{
Sanya Joseph Olurotimi \\ Afe Babalola University, Ado- Ekiti.
}

\begin{abstract}
Objective: The study was conducted to simultaneously display and compare the basic haematological indices (packed cell volume, total and differential white blood count) of subjects with different haemoglobin genotypes. The objective was to highlight the differences which may help in planning interventions and predicting outcomes.
\end{abstract}

Study Design: An outpatient population-based retrospective study was performed. The study covered the period between 1987 and 2011 (25 years). The packed cell volume, haemoglobin genotype, total and differential white blood counts of three hundred and sixty subjects (180 males and 180 females) aged between 1 and 25 years were scrutinized. Only outpatients presenting for malaria were included for comparable morbidity. Patients with co-existing persistent $H b F$ were excluded to avoid misinterpretation of the generated data.

Results: There were significant differences between the haematological indices of the haemoglobin genotypes reviewed in the study.

Conclusion: The Hb genotype should be routinely ordered alongside the other tests and the results interpreted with reference to the Hb Genotype.

key words: Haematological Indices; Haemoglobin Genotype;

\section{Introduction}

Observations coupled with literature review during three decades of general medical practice suggested that haematological profiles are directly or indirectly related to the haemoglobin genotypes (1). This was the basis of a retrospective study covering the period between 1987 and 2011 (25 years). Some studies have considered haematological indices in relation to specific $\mathrm{Hb}$ genotypes (2). However, there is a paucity of comparative studies simultaneously analyzing the haematological indices of different haemoglobin genotypes. Moreover, in many centres, total and differential white cell counts are usually performed without reference to the haemoglobin $(\mathrm{Hb})$ genotype and vice versa except in obvious cases such as HbSS. In areas where haemoglobinopathies are rampant, such as Africa, knowledge of genotype related differences in haematological profiles may be an additional tool in planning interventions and predicting outcome. The present study, an attempt at comparative analysis of the basic haematological indices of the common $\mathrm{Hb}$ genotype variants, was designed to kick-start debate on this rather poorly charted area of haemoglobinopathy.

Materials and Methods:

Three hundred and sixty individual results of haematocrit (pcv), haemoglobin genotype, total and differential white blood counts were obtained from data generated by a standard laboratory located in the university town of Ado- Ekiti, Ekiti State, Nigeria. The results were tabulated under the following headings (Table 1):

- PCV

- $\quad$ HB GENOTYPE

- TOTAL WBC

- NEUTROPHILS

- LYMPHOCYTES

- MONOCYTES

- EOSINOPHILS

The haemoglobin genotypes (Figures 1-6) were presented graphically as a function of the respective haematological indices. The results were subjected to statistical analysis using ANOVA and Student's t-test.

\section{Results}

The results were tabulated (table 1) and also displayed in form of column charts (figures 1 to 6 ) for clarity of comparison. In both the tables and figures, the haematological indices of the $\mathrm{Hb}$ genotype variants ( $\mathrm{HbAC}, \mathrm{HbAS}, \mathrm{HbSC}$ and $\mathrm{HbSS}$ ) as well as HbAA were displayed.

Table 1 shows the average values of the haematological indices obtained for the different haemoglobin genotypes. 
Comparative Analysis Of Haematological Indices Of Haemoglobin Genotypes Aa, Ac, As, Sc And Ss -

Table 1: Average haematological values of subjects studied.

\begin{tabular}{|l|l|l|l|l|l|l|}
\hline \multicolumn{9}{|c|}{ AVERAGE HAEMATOLOGICAL VALUES } & \multicolumn{4}{c|}{$\mathrm{n}=160$} \\
\hline HBG & PCV & WBC & $\mathrm{N}$ & $\mathrm{L}$ & $\mathrm{M}$ & $\mathrm{E}$ \\
\hline AA & 37.39367 & 6515.837 & 45.61538 & 40.90498 & 8.579186 & 4.823529 \\
\hline AC & 41.625 & 5312.5 & 46 & 40.75 & 9 & 5 \\
\hline AS & 37.09091 & 6928.03 & 48.40909 & 38.62121 & 8.545455 & 5.151515 \\
\hline SC & 24.5 & 10275.00 & 50 & 36 & 9.5 & 4.5 \\
\hline SS & 25.73529 & 11151.47 & 51.88235 & 34.58824 & 9.088235 & 4.441176 \\
\hline
\end{tabular}

$\mathrm{HBG}=$ Haemoglobin genotype.

$\mathrm{N}=$ Neutrophils

$\mathrm{M}=$ Monocytes

$\mathrm{PCV}=$ Packed cell volume.

$\mathrm{E}=$ Eosinophils

$\mathrm{WBC}=$ White blood count (total).

$\mathrm{L}=$ Lymphocytes

Table 2 shows the normal reference range for white blood cells.

Table 2: Normal Haematological Indices Reference Range Table:

\begin{tabular}{|l|l|l|}
\hline Item & Description & Value \\
\hline & & $40-52 \%$ (Male) \\
\hline & & \\
\hline & & $37-46 \%$ (Female) \\
\hline & & $31-43 \%$ (Child) \\
\hline Hematocrit (Hct) & & $13.2-16.2 \mathrm{gm} / \mathrm{dL}$ (Male) \\
\hline & & $12.0-15.2 \mathrm{gm} / \mathrm{dL}$ (Female) \\
\hline Red Blood Cell Count (RBC) & & $4.3-6.2 \times 10^{6} / \mu \mathrm{L}$ (Male) \\
\hline & & $3.8-5.5 \times 10^{6} / \mu \mathrm{L}$ (Female) \\
\hline & & $3.8-5.5 \times 10^{6} / \mu \mathrm{L}$ (Infant/Child) \\
\hline White Blood Cell Count (WBC) & & $4.1-10.9 \times 10^{3} / \mu \mathrm{L}$ \\
\hline & Diff & \\
\hline & Polymorphonuclear Cells (polys) & $35-80 \%$ \\
\hline & Immature Polys (bands) & $0-10 \%$ \\
\hline & lymphocytes (lymp) & $20-50 \%$ \\
\hline & monocytes (mono) & $2-12 \%$ \\
\hline & eosinophils (eos) & $0-7 \%$ \\
\hline & basophils (bas) & $0-2 \%$ \\
\cline { 2 - 3 } & & \\
\hline & &
\end{tabular}

Source: W.B Saunders Company (1999).

Figure 1 shows the total WBC profile of the different $\mathrm{Hb}$ genotypes investigated in this study. There was significant $(\mathrm{p}<0.05)$ difference between the wbc values of the different $\mathrm{Hb}$ genotypes.

Total White Blood Cell Count (WBC):

There were significant differences between the average total wbcs of HbAA subjects and those of HbSC $(p<0.05)$ and HbSS $(p<0.01)$ respectively (Figure 1). Both abnormal genotypes had higher values than $\mathrm{HbAA}$, the difference being much more pronounced between $\mathrm{HbAA}$ and $\mathrm{HbSS}$. There was no significant difference ( $p>0.05$ ) between the total wbc counts of HbAA and HbAS. However, HbAC subjects had the lowest average total wbc count, being significantly lower $(\mathrm{p}<0.05)$ than even that of HbAA subjects.

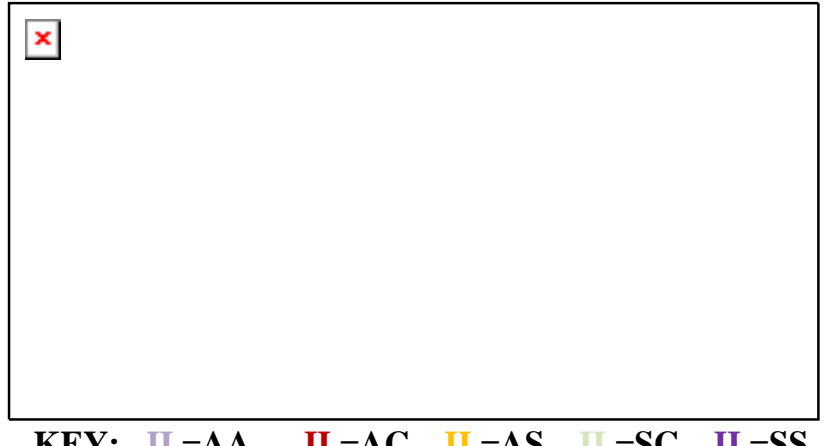

KEY: $\quad$ II $=\mathrm{AA} \quad$ II $=\mathrm{AC} \quad$ III $=\mathrm{AS} \quad I I=\mathrm{SC} \quad$ II $=\mathrm{SS}$

Figure 1: Column chart comparing average total wbc of different $\mathrm{Hb}$ genotypes.

Figure 2 compared the neutrophil counts of the respective $\mathrm{Hb}$ genotypes. There was significant $(\mathrm{p}<0.5)$ difference between the values. 
The average values of the lymphocyte counts obtained with respect to each $\mathrm{Hb}$ genotype were displayed in figure 3 while the respective monocyte, eosinophil and pcv values were presented vide figures 4,5 and 6 respectively.

\section{Neutrophil Count:}

As shown in Figure 2, there was a steady rise in average neutrophil counts above the level in HbAA subjects as we move through $\mathrm{HbAC}, \mathrm{HbAS}, \mathrm{HbSC}$ and HBSS respectively. With the neutrophil count of HbAA as the reference value, the differences were statistically significant: AC $(\mathrm{p}<0.05)$; AS, AC, SC and SS $(\mathrm{p}<0.01)$.

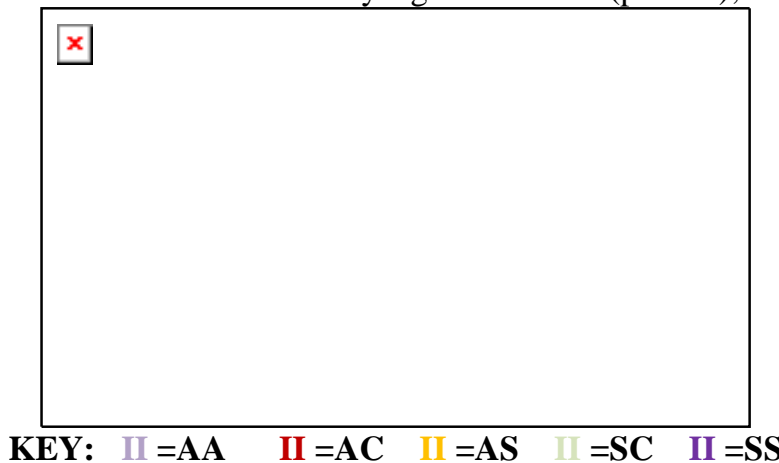

Figure 2: Column chart comparing average neutrophils counts.

\section{Lymphocyte count (Figure 3):}

The lymphocyte counts declined in value from HbAA to HbSS in reverse order to the neutrophil counts (compare Figures 2 and 3). Thus, the highest average value was obtained for HbAA and the least for HbSS (Table 1, Figure 3). There were significant differences between the lymphocyte counts of the abnormal haemoglobins and HbAA.

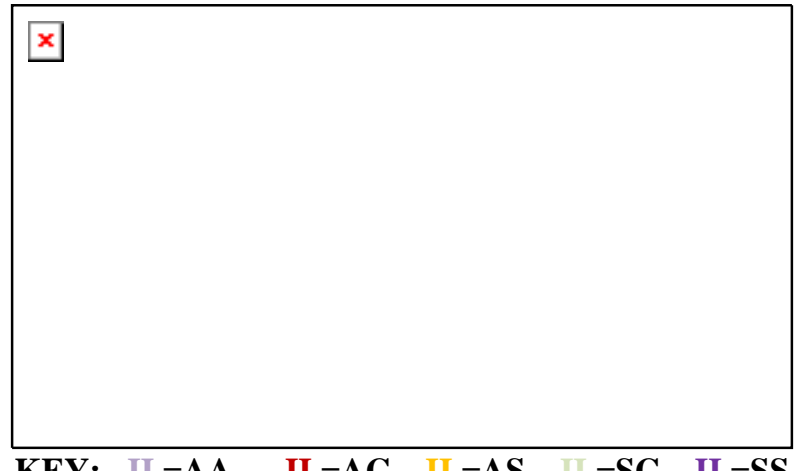

KEY: $\quad$ III =AA $\quad$ II $=\mathrm{AC} \quad$ III $=\mathrm{AS} \quad$ III $=\mathrm{SC} \quad$ II $=\mathrm{SS}$

Figure 3: Column chart comparing average lymphocyte counts.

\section{Monocyte counts:}

HbSC had the highest monocyte count followed by SS, AC, AA and SC in descending order. The difference between $\mathrm{SC}$ and the other respective indices was highly significant $(\mathrm{p}<0.01)$. SS values were slightly higher than AC figures $(\mathrm{p}<0.05)$. There was no significant difference between AA and AS monocyte counts but $\mathrm{AC}$ and SS counts were significantly higher $(\mathrm{p}<0.05)$ than those of AA and AS respectively.

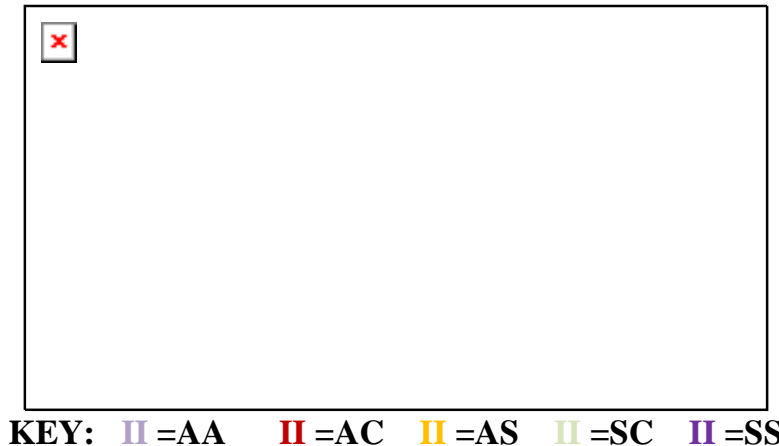

Figure 4: Column chart comparing average monocyte counts. 


\section{Eosinophil Counts:}

The highest eosinophil count was recorded in AS subjects. Lower levels were recorded in AC, AA, SC and SS in descending order. There were significant differences between individual genotypes $(\mathrm{p}<0.05)$.

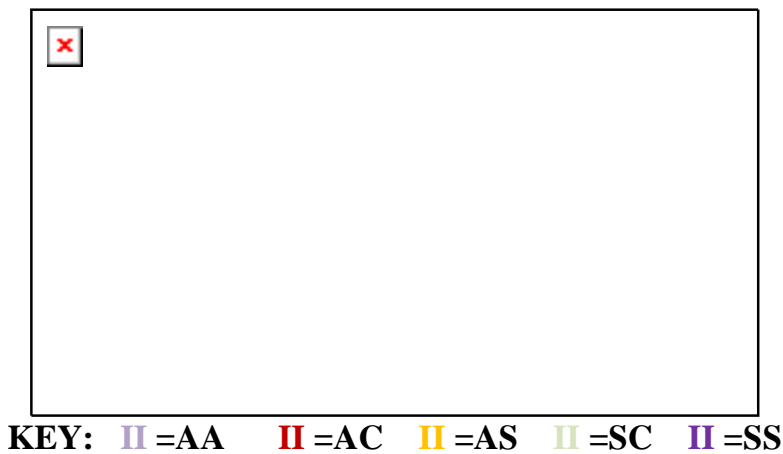

Figure 5: Column chart comparing average Eosinophil counts

\section{Packed Cell Volume:}

The different haemoglobin genotypes showed variations in the PCV or Haematocrit values (Table 1, Figure 6). The average PCV of HbAA subjects was significantly higher than that of $\mathrm{HbSS}(\mathrm{p}<0.01)$. Also, HbSC subjects have an average haematocrit significantly $(\mathrm{p}<0.01)$ lower than that of HbAA. However, there was no significant difference $(\mathrm{p}>0.05)$ between the haematocrit values of Hb SC and HbSS. Similarly, the values for HbAA and HbAS were not significantly different ( $p>0.05)$. However, the results showed that HbAC subjects had significantly higher $(\mathrm{p}<0.05)$ average haematocrit values than HbAA (Table 1nd Figure 6). Consequently, average values for HbAC subjects were much higher $(\mathrm{p}<0.01)$ than those of $\mathrm{HbSC}$ and $\mathrm{HbSS}$ subjects respectively.

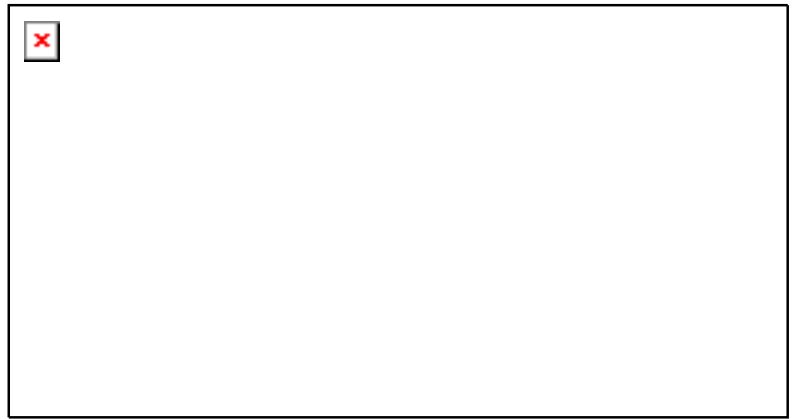

KEY: $\quad$ III =AA II =AC $\quad$ III $=\mathrm{AS} \quad$ III $=\mathrm{SC} \quad$ II $=\mathrm{SS}$

Figure 6: Column chart comparing PCV of different $\mathrm{Hb}$ genotypes.

In summary, $\mathrm{Hb} \mathrm{AA}$ subjects had the highest lymphocyte and the lowest neutrophil counts respectively. HbAC subjects recorded the highest pcv and the lowest total wbc count. Hb AS subjects had the highest monocyte and eosinophil counts. HbSC subjects had the lowest pcv and the highest total wbc and monocyte counts. The subjects with HbSS genotype had the highest total wbc and neutrophil counts respectively. The lowest eosinophil count was also recorded in the group.

\section{Haematological Indices:}

\section{Discussion:}

Haematological indices refer to the specific constituents of the blood such as haemoglobin, haematocrit, red blood cells and white blood cells (3). A range of normal values is ascribed to each of these indices and such values are accepted universally. However, there are variations in what is accepted as normal depending on the reference population being studied (4). Normal values may also vary slightly between laboratories within the same geographical location (5). Normal ranges of haematological values are shown in Table 2.

\section{Haemoglobin genotypes and Haematological indices:}

The results obtained in the present study correlated significantly with those earlier reported from the reference centres (6). For instance, the neutrophil count was observed to correlate well with results obtained in earlier studies. The highest level was consistently observed in HbSS subjects. This observation has been attributed to some factors intrinsic to the HbSS genotype such as: 
Comparative Analysis Of Haematological Indices Of Haemoglobin Genotypes Aa, Ac, As, Sc And Ss -

a) Continuous bone marrow stimulation as a result of the perennial haemolysis.

b) Frequent infections due to the poor handling of encapsulated bacteria by HbSS subjects.

c) Immune mediated responses of granulocytes to various pathogens (7).

However, there were some differences between the results in the present study and earlier studies. The lowest total wbc count was found in $\mathrm{HbAC}$ subjects in the present study rather than in HbAA subjects as previously reported (4). The discrepancy may be due to differences in methodology adopted for the studies but the observation deserves further scrutiny.

Eosinophil counts were on the high side in all the subjects investigated. This didnot come as a surprise since majority of the subjects were rural and semi-urban dwellers with constant exposure to parasitic infestations. It is however noteworthy that relatively low eosinophil counts were observed in $\mathrm{Hb}$ SS (4.44\%) and HbSC $(4.50 \%)$ subjects respectively. There was no significant difference ( $p>0.05$ ) between the eosinophil counts of the two groups. However, the lowest eosinophil count was observed in HbSS subjects. The relatively low eosinophil counts may indicate that these individuals respond poorly to parasites and other allergens as a component of the larger immunological compromise. This may partly explain the poor handling of malaria parasites by these individuals. It may also account for the frequently observed severity of the infection apart from the haemolysis triggered by parasitaemia. This is more so in view of the fact that malaria infection does not always cause clinically significant haemolytic anemia even in the SC and SS subjects (personal observation over thirty years).

\section{Conclusion}

Observed differences in haematological indices among the population could be partly explained based on genotype differences among other factors. Reasonably accurate predictions of possible profiles and interpretations of the haematological indices of subjects with the various $\mathrm{Hb}$ genotypes could also be made. The $\mathrm{Hb}$ genotype should be routinely ordered alongside the other tests and the results interpreted with reference to the $\mathrm{Hb}$ Genotype. For instance, a relatively low pcv may not necessarily call for emergency blood transfusion if the genotype is known to be SS and the patient is clinically stable. Such individual may be an HbSS patient in steady state. There is urgent need to take a closer look at the implications of the findings in this study by further investigations designed to address specific haematological indices in relation to the genotypes. The respective roles of the genes and environment should also be of interest in further research. The effect of disease states on the findings should also be considered. It is believed that the results obtained in the present study should be reproducible in larger studies and other settings.

\section{References:}

[1]. $\quad \mathrm{El}$ - Hazim MAF and Warsy AS. (2001). Normal reference values for haematological parameters, red cell indices, $\mathrm{Hb} \mathrm{A} 2 \mathrm{and} \mathrm{Hb} F$ from early childhood through adolescence in Saudi. Annals of Saudi Medicine. 21: 165 - 169

[2]. Imoru Momodu, Kabiru Suleiman, Shehu Abdullahi, Umar A. Shehu. (2011). Haematological values in Nigerian children with steady state homozygous sickle cell disease. International Journal of Academic Research.

[3]. Vol. 3. No.1.

[4]. Wild BJ and Bain BJ. (2001). Investigation of abnormal heamoglobins and thalassaemia. In: Dacie and Lewis Practical Haematology. Lewis SM, Bain BJ and Bates I (eds).9th edition. Churchill Livingstone, London. Pp 231 - 266.

[5]. Lewis SM, Bain BJ and Bates I (eds). (2001).Haematology. 9th edition. Churchill Livingstone,London. pp 19 -42. El - Hazim MAF and Warsy AS. (2001). Normal reference values for haematological parameters, red cell indices, A2 and Hb F from early childhood through adolescence in Saudi. Annals of Saudi Medicine 21: 165 - 169 .

[6]. Dapper DV, Nwauche CA and Siminialayi IM. (2000).Some haematological refrence values for pre -primary and primary school aged children in Port-Harcourt, Nigeria. Niger J Clin Pract 12: 262 -267. (2009).

[7]. Awogu AU. (2000). Leucocyte counts in children with sickle cell anaemia: usefulness of stable state values during infections. Wesr Afr J Med 19: $55-58$

\section{Acknowledgments}

Akinyemi Olumide Felix of the department of Laboratory Science, Afe Babalola University, Ado- Ekiti for tracking the laboratory records containing the data used in this study. 